Article

\title{
Suppression of STAT3 Phosphorylation and RelA/p65 Acetylation Mediated by MicroRNA134 Plays a Pivotal Role in the Apoptotic Effect of Lambertianic Acid
}

\author{
Deok Yong Sim ${ }^{\dagger}$, Hyo-Jung Lee ${ }^{\dagger}$, Ji Hoon Jung ${ }^{\circledR}$, Eunji Im, Jisung Hwang, Dong Sub Kim and \\ Sung-Hoon Kim *(D) \\ College of Korean Medicine, Kyung Hee University, Seoul 02447, Korea; Simdy0821@naver.com (D.Y.S.); \\ hyonice77@naver.com (H.-J.L.); johnsperfume@khu.ac.kr (J.H.J.); ji4137@naver.com (E.I.); \\ hjsung0103@naver.com (J.H.); dongsoub@hanmail.net (D.S.K.) \\ * Correspondence: sungkim7@khu.ac.kr; Tel.: +82-2-961-9233 \\ + These authors contributed equally to this work.
}

Received: 28 May 2019; Accepted: 17 June 2019; Published: 19 June 2019

\begin{abstract}
As p300-mediated RelA/p65 hyperacetylation by signal transducers and activators of transcription 3 (STAT3) is critical for NF- $\mathrm{kB}$ activation, in the current study, the apoptotic mechanism of lambertianic acid (LA) was explored in relation to STAT3 phosphorylation and RelA/p65 acetylation in MCF-7, DU145, PC-3, and MDA-MB-453 cells. LA significantly increased the cytotoxicity, sub G 1 population, and the cleavage of poly (ADP-ribose) polymerase (PARP) in MDA-MB-453 or PC-3 cells (STAT3 mutant), more than in the MCF-7 or DU145 cells (STAT3 wild). Consistently, LA inhibited the phosphorylation of STAT3 and nuclear factor kappa-light-chain-enhancer of activated B cells (NF- $\mathrm{kB}$ ), and disrupted the interaction between p-STAT3, p300, NF- $\mathrm{kB}$, and RelA/p65 acetylation (Ac-RelA/p65) in the MCF-7 and DU145 cells. Also, LA reduced the nuclear translocation of STAT3 and NF- $\mathrm{BB}$ via their colocalization, and also suppressed the protein expression of XIAP, survivin, Bcl-2, Bcl-xL, vascular endothelial growth factor (VEGF), Cox-2, c-Myc and mRNA expression of interleukin 6 (IL-6), and tumor necrosis factor- $\alpha$ (TNF- $\alpha$ ) in MCF-7 cells. Conversely, IL-6 blocked the ability of LA to suppress the cytotoxicity and PARP cleavage, while the depletion of STAT3 or p300 enhanced the PARP cleavage of LA in the MCF-7 cells. Notably, LA upregulated the level of miRNA134 and so miRNA134 mimic attenuated the expression of pro-PARP, p-STAT3, and Ac-RelA, while the miRNA134 inhibitor reversed the ability of LA to reduce the expression of Ac-RelA and pro-PARP in MCF-7 cells. Overall, these findings suggest that LA induced apoptosis via the miRNA-134 mediated inhibition of STAT3 and RelA/p65 acetylation.
\end{abstract}

Keywords: Lambertianic acid; STAT3; NF-kB; p300; Ac-RelA/p65

\section{Introduction}

Signal transducers and activators of transcription 3 (STAT3), a member of a family of seven proteins (STATs 1, 2, 3, 4, 5a, 5b, and 6), is involved in proliferation, angiogenesis, metastasis, and immunosuppression [1]. Interleukin 6 (IL-6) activates STAT3 via the phosphorylation of tyrosine 705 [2], while STAT3 inhibitors, such as STA-21 [3], Stattic [4,5], S31-201 [6], and BP-1-102 [7], inhibit the phosphorylation of STAT3 [8] via interaction with the STAT3 SH-2 domains.

Accumulating evidence has revealed that $\mathrm{p} 300$-mediated RelA/p65 hyperacetylation by STAT3 is essential for NF- $\mathrm{KB}$ activation in several cancers [9], as protein hyper-acetylation in cells is activated 
in inflammation and cancers [10]. In the same line, acetylation, like phosphorylation, is important in regulating the nuclear translocation of NF- $\mathrm{kB}$ [11].

Hence, recently several research projects have been conducted using natural compounds targeting the hypoacetylation of p65 by directly inhibiting the activity of p300 histone acetyltransferase (HAT) enzymes (acetyltranferase) [12,13]. Indeed, anacardic acid [14], gallic acid [13], and epigallocatechin gallate (EGCG) [12] suppressed NF- $\mathrm{KB}$ and its regulated gene products by inhibiting p65 acetylation.

MicroRNAs (miRNAs), 20-22 nucleotide non-coding RNAs, were known to work mainly as post-transcriptional regulators of mRNAs [15]. Among them, miR134 suppresses the proliferation and epithelial-mesenchymal transition (EMT) in colorectal and renal cancers [16], as a tumor suppressor through the KRAS-mediated mitogen-activated protein kinase (MAPK)/ extracellular-signal-regulated kinase (ERK) pathway [17].

Lambertianic acid (LA; Figure 1a), a major component of Pinus koraiensis, was known to have anti-obesity [18], anti-inflammatory [19], and anti-cancer effects [20-22]. Nevertheless, the underlying molecular mechanisms of LA were not fully understood in association with STAT3 phosphorylation and RelA/p65 acetylation. Hence, in the present work, the apoptotic mechanism of LA was examined in the MCF-7 and DU145 (STAT3 wild type), MDA-MB-453 (STAT3 mutant), and PC-3(STAT3 null) cell lines [23], in association with the miR134 mediated suppression of STAT3 and RelA/p65 acetylation.

\section{Results}

\subsection{LA Induced Cytotoxicity and Sub-G1 Accumulation Increased the Cleavage of Poly (ADP-Ribose) Polymerase (PARP) in STAT3-Dependent or STAT3-Independent Cancer Cells}

To evaluate the specific apoptotic effect of LA in STAT3-dependent or independent cancer cells, a cytotoxicity assay was conducted in breast cancer (MDA-MB-453; STAT3 mutant, MCF-7; STAT3 wild type) and prostate cancer (PC-3; STAT3 null, DU145; STAT3 wild type) cell lines by 3-(4,5-dimethylthiazol-2-yl)-2,5diphenyltetrazolium bromide (MTT) assay. Here, LA reduced the viability of the DU145, PC-3 cells, MCF-7, and MDA-MB-453 cells in a dose-dependent manner (Figure 1b). However, the cytotoxicity of LA was better in the MDA-MB-453 and PC-3 cells than in the MCF-7 and DU145 cells. Consistently, the cell cycle analysis revealed that LA at $30 \mu \mathrm{M}$ increased the sub-G1 population to $42.75 \%$ in MDA-MB- 453 , more than $6.84 \%$ of the MCF-7 cells (Figure 1c). Also, LA enhanced the cleavages of PARP in the MDA-MB-453 and PC-3 cells better than in the MCF-7 and DU145 cells (Figure 1d).

\subsection{LA Suppressed the Phosphorylation of STAT3 and NF- $k B$, and the Expression of $p 300$ and RelA} Acetylation in MCF-7 and DU145 Cells

To determine the role of STAT3 in LA-induced apoptosis, Western blotting was conducted in MCF-7 and DU145 cells. As shown in Figure 2a, LA attenuated the phosphorylation of STAT3 and NF- $\mathrm{kB}$, and also reduced the expression of p300 and RelA/p65 acetylation in MCF-7 and DU145 cells. Consistently, LA effectively suppressed the nuclear translocation of p-STAT3 and NF-kB p65 via their co-localization in MCF-7 cells (Figure 2b). 


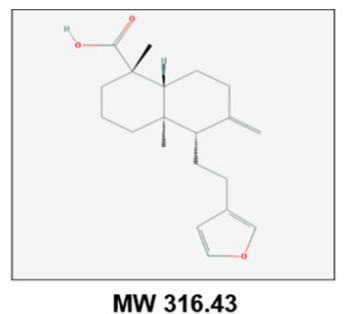

(a)
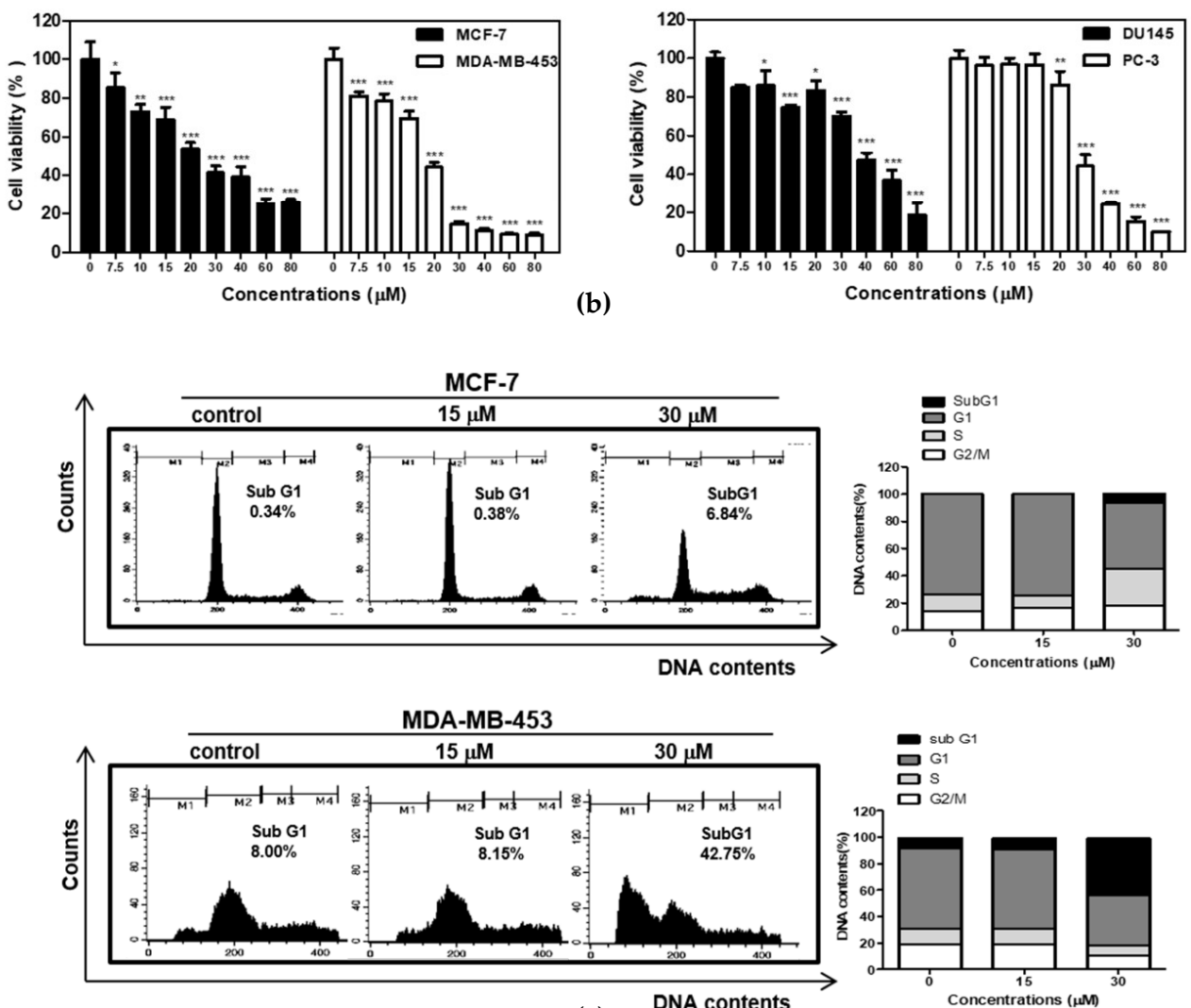

(c)
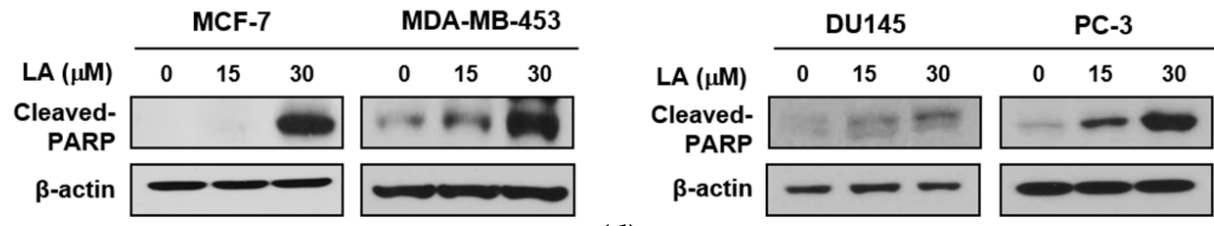

(d)

Figure 1. Effect of lambertianic acid (LA) on cytotoxicity and apoptosis in MCF-7, MDA-MB-453, DU145, and PC-3 cancer cells. (a) The chemical structure of LA. (b) The effect of LA on cytotoxicity in MCF-7, MDA-MB-453, DU145, and PC-3 cells. The cells were distributed onto 96-well plates and were exposed to indicated concentrations of LA $(0,7.5,10,15,20,30,40,60$, and $80 \mu \mathrm{M})$ for $24 \mathrm{~h}$. The cell viability was calculated using a 3-(4,5-dimethylthiazol-2-yl)-2,5diphenyltetrazolium bromide (MTT) assay. The data stand for means \pm standard deviation (SD). ${ }^{*} p<0.05,{ }^{* *} p<0.01,{ }^{* * *} p<0.001$. (c) Effect of LA on the sub-G1 population in MCF-7 and MDA-MB-453 cells, by cell cycle analysis. The MCF7 and MDA-MB-453 cells were exposed to LA $(0,15$, and $30 \mu \mathrm{M})$ for $24 \mathrm{~h}$, and were stained with propidium iodide (PI) for flow cytometric analysis. The bar graphs represent the quantification of the cell cycle population (\%). (d) The effect of LA on the poly (ADP-ribose) polymerase (PARP) cleavage in the MCF-7 and MDA-MB-453 cells. The MCF-7 and MDA-MB-453 cells were treated with LA $(0,15$, and $30 \mu \mathrm{M}$ ) for $24 \mathrm{~h}$, and were subjected to Western blotting with the antibody of the cleaved PARP. 

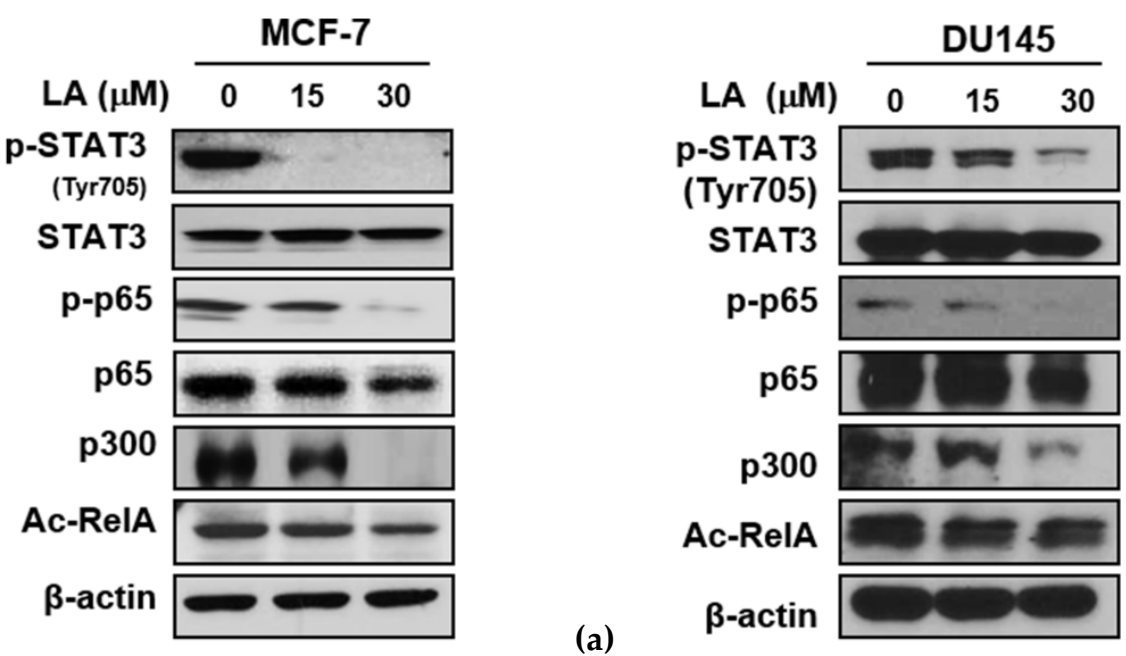

(a)

\section{MCF-7}

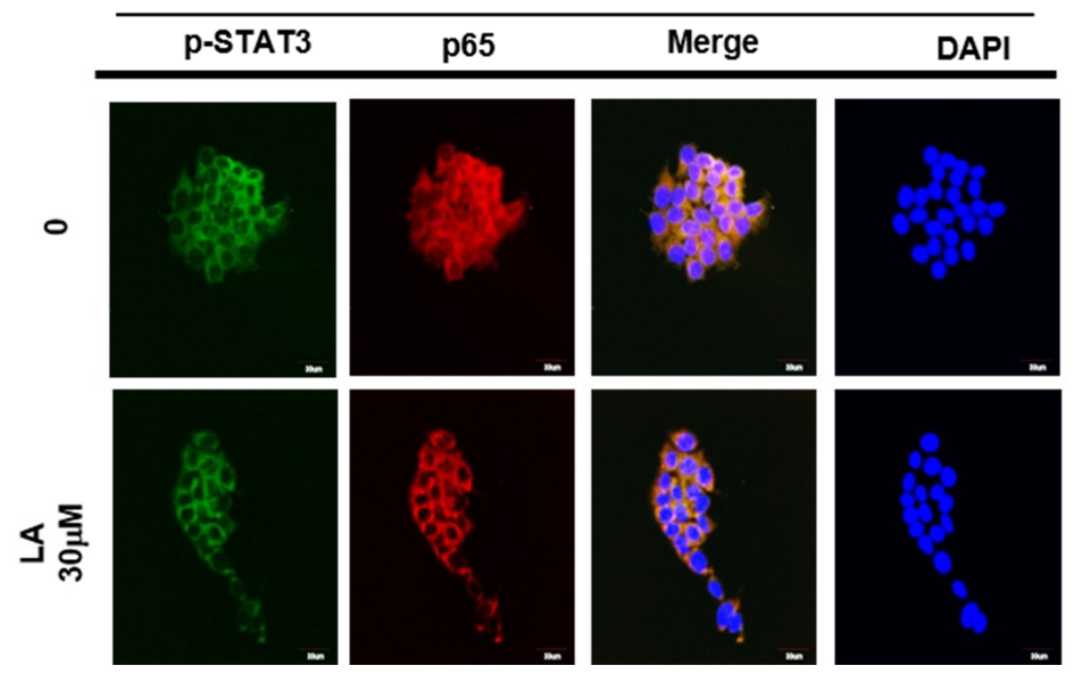

(b)

Figure 2. Effect of LA on the expression of the p-signal transducers and activators of transcription 3 (STAT3), p-NF- kB, p300, and Ac-RelA, and their nuclear translocation in MCF-7 and DU145 cells. (a) Effect of LA on p-STAT3, p-NF-kB, p300, and Ac-RelA in MCF-7 and DU145 cells. The cells were treated with LA $(0,15$, and $30 \mu \mathrm{M})$ for $24 \mathrm{~h}$, and were subjected to Western blotting for p-JAK2, p-STAT3, STAT3, p-p65/RelA, NF-кB. p300, and Ac-RelA. (b) Effect of LA on nuclear translocation in the MCF-7 cells. Immunostaining was conducted with antibodies of p-STAT3 and RelA/p65, and secondary fluorescein isothiocyanate (FITC)-conjugated antibody in the MCF-7 cells treated with or without LA.

\subsection{LA Attenuated the Expression of NF- $\mathrm{kB}$ Regulated Genes in MCF-7 Cells}

To confirm the p65 acetylation inhibition of LA, Western blotting and qRT-PCR were conducted in MCF-7 cells. Consistently, the LA attenuated the expression of the NF- $\mathrm{KB}$ regulated genes, including Bcl-2, Bcl-xL, XIAP, survivin, (anti-apoptotic proteins), VEGF (angiogenic protein), COX-2 (inflammatory protein), and c-Myc (oncogenic genes) in the MCF-7 cells (Figure 3a). Also, STAT3 activators IL-6 and TNF- $\alpha$ (inflammatory factor) were downregulated at the mRNA level in the LA-treated MCF-7 cells (Figure 3b). 

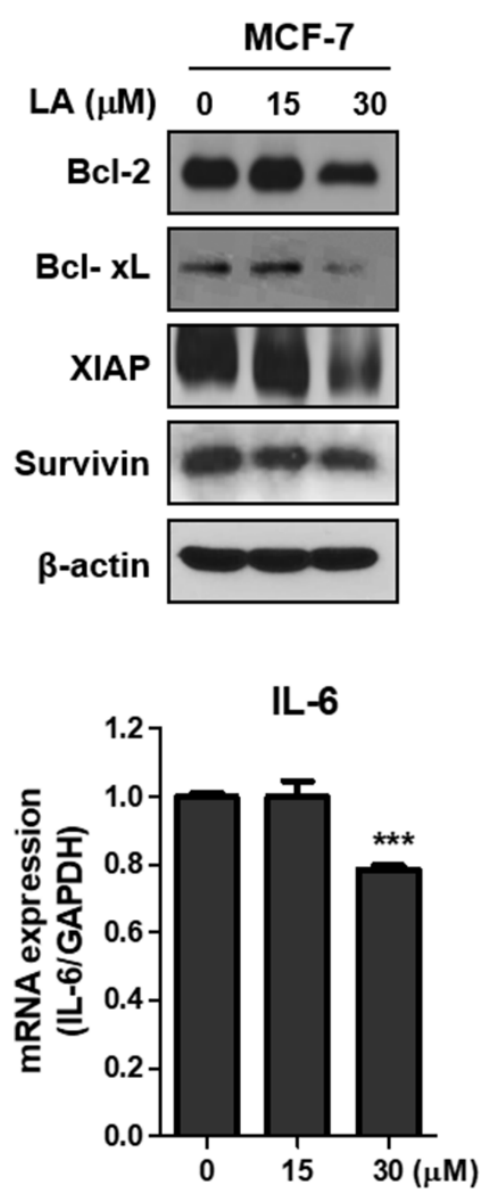

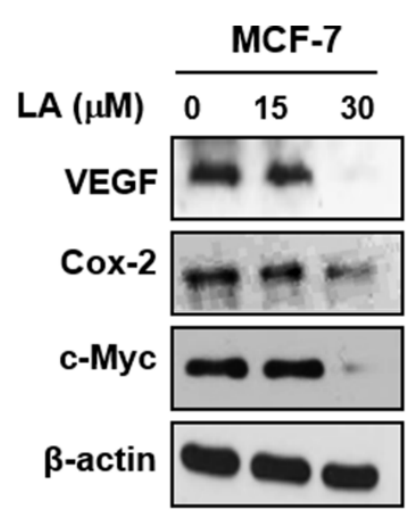

(a)

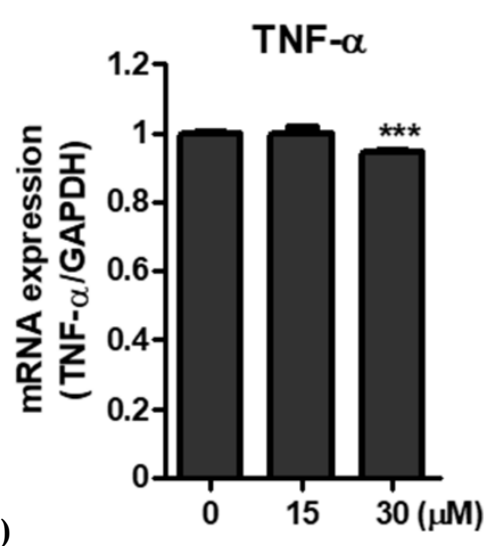

Figure 3. Effect of LA on NF-kB-regulated proteins in MCF-7 cells. (a) Effect of LA on NF-kB-modulated genes in MCF-7 cells. The MCF-7 cells were treated with LA $(0,15$, and $30 \mu \mathrm{M})$ for $24 \mathrm{~h}$, and were subjected to Western blotting for Bcl-2, Bcl-xL, XIAP, survivin, VEGF, COX-2, c-Myc, and $\beta$ actin. (b) Effect of LA on TNF- $\alpha$ and interleukin 6 (IL-6) at the mRNA level in the MCF-7 cells by qRT-PCR. Data stand for means \pm SD. ${ }^{* * *} p<0.001$ vs. untreated control.

\subsection{STAT3 Inducer IL-6 Suppressed Cytotoxic and Apoptotic Effects of LA in MDA-MB-453 Cells}

To verify the critical role of STAT3 in the cytotoxic and apoptotic effect of LA, MTT assay, Western blotting, and cell cycle analysis were conducted in IL-6-treated MDA-MB-453 cells. Here, IL-6 disturbed the cytotoxicity of LA (Figure 4a), and also reduced the sub-G1 population to $12.11 \%$ compared to the LA-alone treated control (22.43\%) in IL-6 treated MDA-MB-453 cells (Figure 4c). Consistently, the IL-6 treatment blocked the capacity of LA to induce PARP cleavage (Figure 4b); decrease the phosphorylation of STAT3, IkB, and p65; and reduce the expression of p300 and Ac-RelA in MDA-MB-453 cells compared to the untreated control (Figure 4d). Conversely, the depletion of STAT3 or p300 enhanced the PARP cleavage and the inhibition of Ac-RelA A by LA in the MCF-7 cells (Figure 4e,f). 


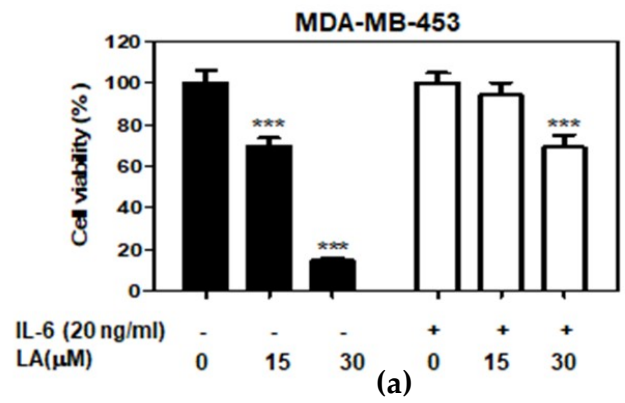

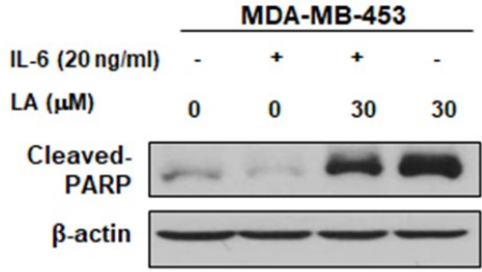

(b)

MDA-MB-453

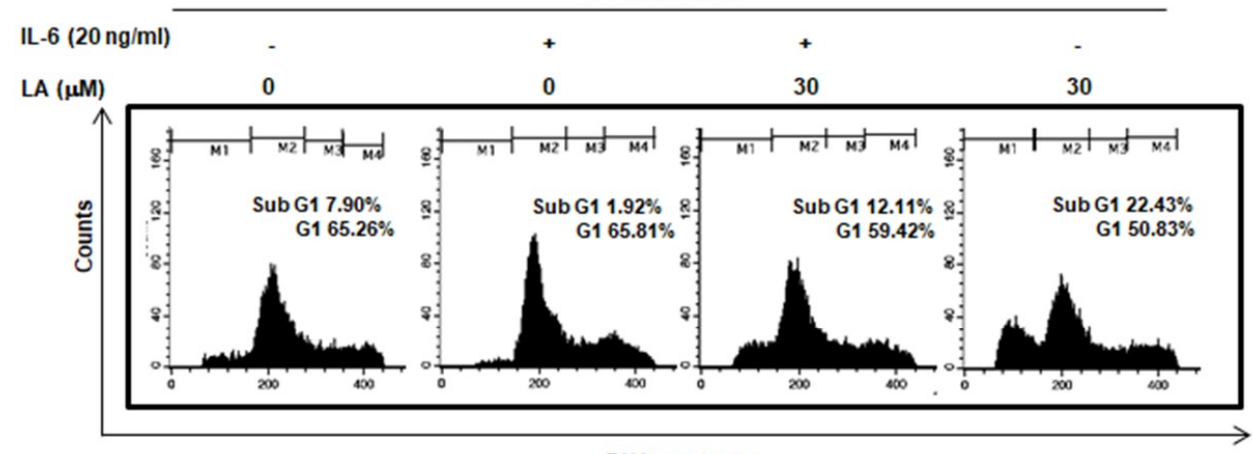

DNA contents

(c)

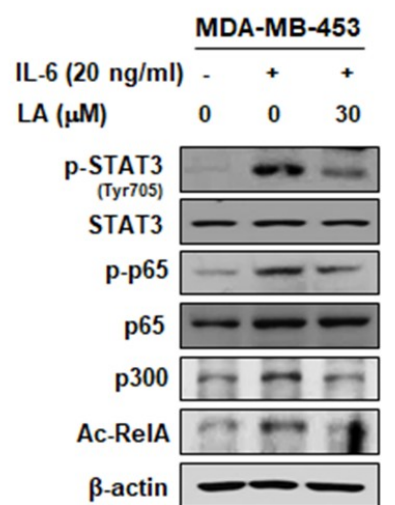

(d)

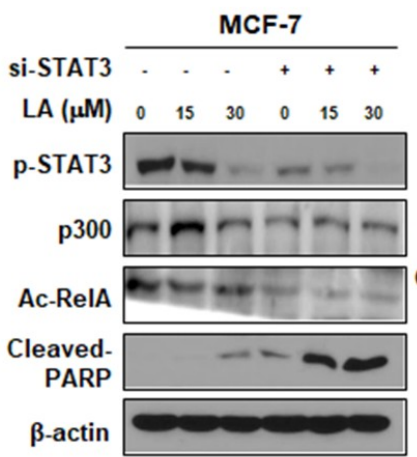

(e)

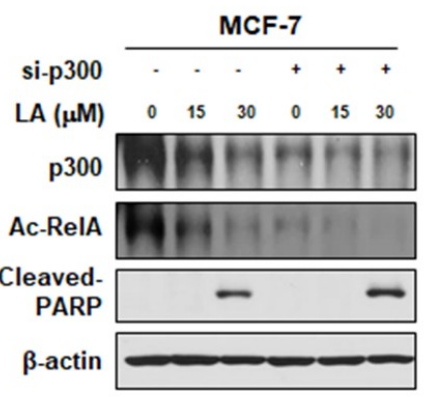

(f)

Figure 4. Effect of IL-6 or the depletion of STAT3 or p300 on the cytotoxic and apoptotic effects by LA in MCF-7 and MDA-MB-453 cells. (a) Effect of LA on the cytotoxicity of LA in IL-6-treated MDA-MB-453 cells. The cells were exposed to LA $(0,15$, and $30 \mu \mathrm{M})$ for $24 \mathrm{~h}$, with or without IL-6 $(20 \mathrm{ng} / \mathrm{mL})$. The cell viability was calculated by 3-(4,5-dimethylthiazol-2-yl)-2,5diphenyltetrazolium bromide (MTT) assay. (b) Effect of LA on the PARP cleavage in the IL-6-treated MDA-MB-453 cells. The cells were exposed to LA $(30 \mu \mathrm{M})$ for $6 \mathrm{~h}$, with or without IL-6 $(20 \mathrm{ng} / \mathrm{mL})$. Cell lysates were prepared and subjected to Western blotting for PARP. (c) The effect of LA on the sub-G1 population in the IL-6-treated MDA-MB-453 cells. The cells were exposed to LA $(30 \mu \mathrm{M})$ for $6 \mathrm{~h}$, with or without IL-6 $(20 \mathrm{ng} / \mathrm{mL})$ stimulation, and cell cycle analysis was conducted. (d) The cell lysates prepared from the MDA-MB-453 cells were subjected to Western blotting for p-STAT3, STAT3, and p-p65/RelA. (e) The effect of STAT3 depletion on p-STAT3, p-p65, p300, Ac-RelA, and cleaved PARP in the LA-treated MCF-7 cells. The cells transfected with p-STAT3 or scrambled siRNA plasmid $(40 \mathrm{nM})$ for $24 \mathrm{~h}$ were exposed to LA $(30 \mu \mathrm{M})$ for $24 \mathrm{~h}$, and were subjected to Western blotting for p-STAT3, STAT3, p65, p300, and Ac-RelA. (f) The effect of p300 depletion on p300, Ac-RelA, and cleaved PARP in the LA-treated MCF-7 cells. The cells transfected with either p300 or scrambled siRNA plasmid $(40 \mathrm{nM})$ for $24 \mathrm{~h}$ were exposed to LA $(0,15$, and $30 \mu \mathrm{M})$ for $24 \mathrm{~h}$, and subjected to Western blotting with antibodies of p300, Ac-RelA, and cleaved-PARP. 
2.5. LA Inhibited the Expression of $p 300$ and RelA/65 Acetylation, and Disrupted the Interaction between p-STAT3, p300, and NF- $\kappa$ B in MCF-7 and DU145 Cells

To validate whether LA inhibits the p300-mediated RelA/p65 acetylation, immunofluorescence and co-immunoprecipitation (IP) were performed in MCF-7 and DU145 cells. As shown Figure 5a, the scores of the protein-protein interactions (PPI) between STAT3 and p300, STAT3 and p65, or p65 and p300 were $0.970,0.820$, and 0.981, respectively. IP revealed that LA disrupted the binding between p-STAT3, p300, and RelA (p65) after treatment with LA for $24 \mathrm{~h}$, in the MCF-7 and DU145 cells (Figure 5b).
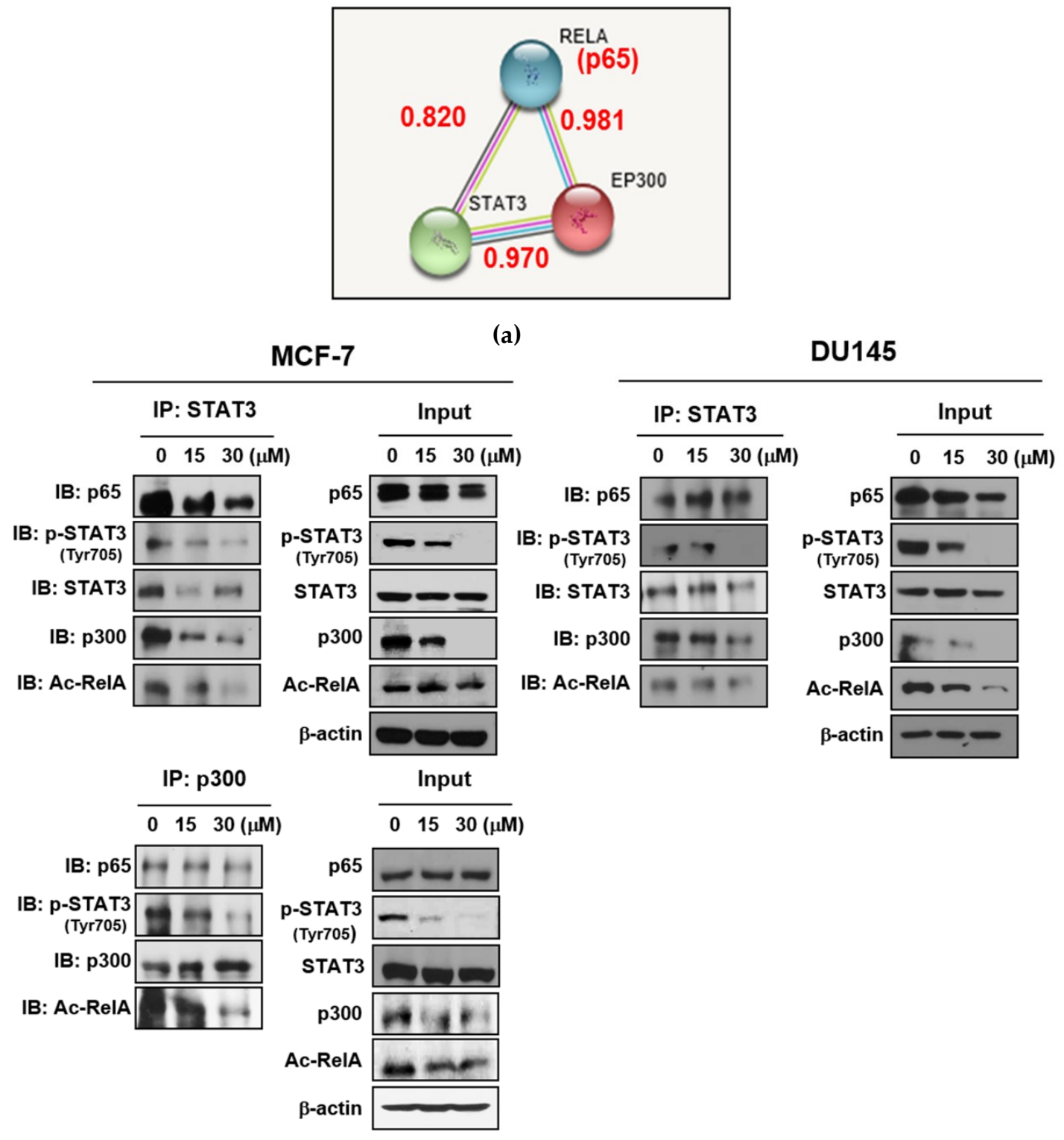

(b)

Figure 5. Effect of LA on the interaction between p-STAT3, p300, and RelA in the MCF-7 and DU145 cells. (a) Protein-protein interaction (PPI) scores between STAT3, p300, and RelA/p65 by search tool for the retrieval of interacting genes/proteins (STRING) database. (b) MCF-7 and DU145 cells were treated with LA for $24 \mathrm{~h}$. Immunoprecipitation (IP) was performed with cell lysates, using antibodies of STAT3 and p300, and Western-blot analysis was conducted to detect RelA/p65, p-STAT3, STAT3, p300, and Ac-RelA in the whole cell lysates. IB-immunoblotting. 


\section{6. miR134 Plays a Pivotal Role in the LA-Induced Apoptotic Effect in MCF-7 Cells}

To identify the role of miR134 in the LA-induced apoptotic effect in MCF-7 cells, the miR134-mimic or -inhibitor plasmid was transfected into MCF-7 cells. Here, LA increased the expression of miR134 in the MCF-7 cells by RT-PCR (Figure 6a). The miR134-mimic attenuated the expression of the pro-PARP, p-STAT3, and Ac-RelA in MCF-7 cells (Figure 6b). In contrast, the miR134 inhibitor reversed the cytotoxicity and inhibition of pro-PARP and Ac-RelA by LA in the MCF-7 cells (Figure 6c,d).

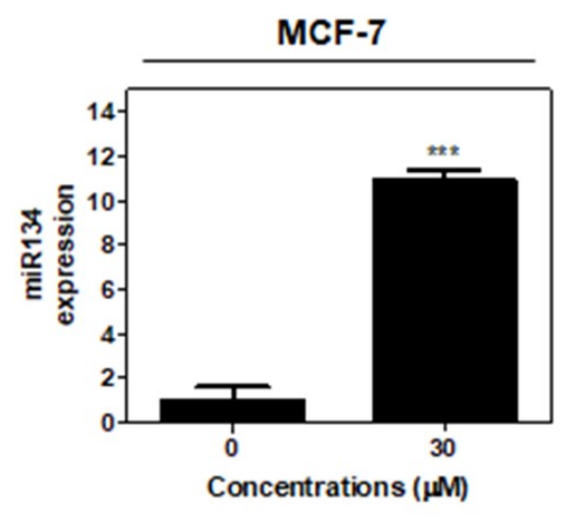

(a)

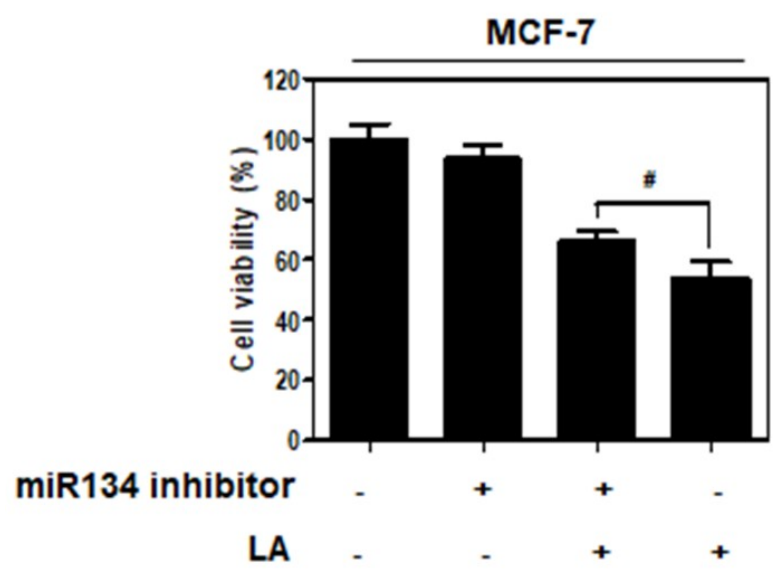

(c)

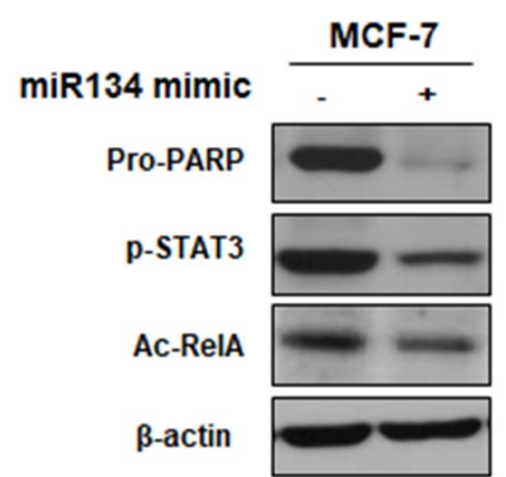

(b)

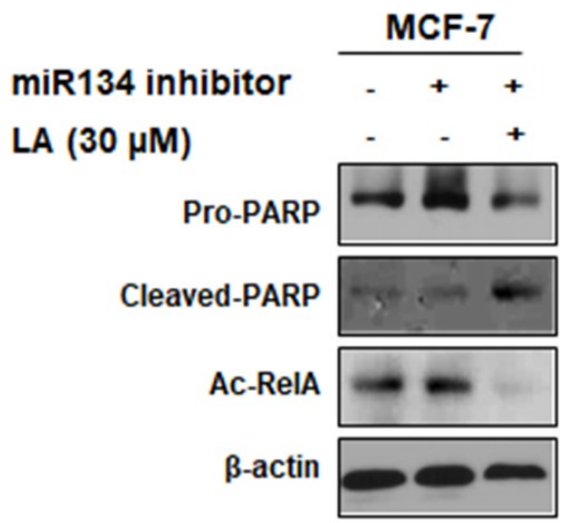

(d)

Figure 6. The pivotal role of miR134 in the LA-induced apoptotic effect in MCF-7 cells. (a) Effect of LA on the miR134 level in MCF-7 cells by qRT-PCR. ${ }^{* * *} p<0.001$ vs. untreated control. (b) Effect of miR134 mimic on PARP, p-STAT3, and Ac-RelA in the MCF-7 cells. (c) Effect of the miR134-inhibitor on the viability of the MCF-7 cells with or without LA. \# $p<0.05$ vs. LA alone treated control. (d) Effect of the miR134-inhibitor on PARP and Ac-RelA in the MCF-7 cells. Data represent means \pm SD.

\section{Discussion}

The aim of the current work is to elucidate the underlying apoptotic mechanism of LA in association with STAT3 and NF- $\mathrm{KB}$ signaling in breast and prostate cancer cells. Herein, MDA-MB-453 and PC-3 STAT3 mutant cells were more susceptible to the cytotoxicity of LA, compared with MCF-7 and DU145 STAT3 wild-type cells. Likewise, LA significantly increased sub-G1 accumulation along with an increased cleavage of PARP in the MDA-MB-453 and PC-3 cells, more than in the MCF-7 and DU145 cells, implying the important role of STAT3 in the cytotoxic and apoptotic effect of LA.

Accumulating evidence has revealed that STAT3 and NF- $\mathrm{KB}$ are involved in a variety of biological processes, such as inflammation, and cancer progression and growth [24,25]. Thus, STAT3 and NF- $\mathrm{kB}$ can be considered as potent target molecules for cancer therapy $[26,27]$. Our Western blotting showed 
that LA treatment suppressed the phosphorylation of STAT3 and NF- $\mathrm{KB}$, and the nuclear translocation of STAT3 and NF- $\mathrm{kB}$, indicating the involvement of STAT3 and NF- $\mathrm{kB}$ pathways in LA-induced apoptosis in MCF-7 and DU145 cells.

Recent evidence has demonstrated that STAT3 is upregulated in most cancers, and NF- $\mathrm{kB}$ enhances the STAT3-p300 interaction [9]. Also, the accumulation of RelA/p65 in the nucleus can be promoted by acetylation by p300 [28], and STAT3 is essential for p300-mediated RelA acetylation [29,30]. Through the close interaction between STAT3 and NF- $\mathrm{B}$, STAT3 increases the NF- $\mathrm{kB}$ activity, and also, the persistent activation of STAT3 is dependent on NF- $\mathrm{KB}$ signaling [9,31]. It is well documented that several inflammatory cytokines, including IL-6, COX-2, and IL-23, activate STAT3 through NF-kB regulated inflammatory responses, and RelA/p65 is maintained through p300-mediated RelA/p65 acetylation by STAT3 [29]. Here, LA attenuated the expression of p300 and RelA/p65 acetylation (Ac-RelA), and also disrupted the binding of p-STAT3 with p300 or Ac-RelA in MCF-7 and DU145 cells, indicating that LA induces the hypoacetylation of RelA/p65, leading to the downregulation of

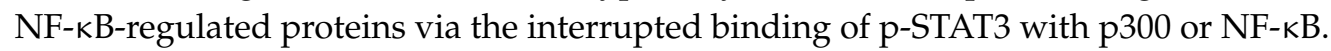

As p300 HAT is closely associated with RelA/p65 acetylation in cancer progression [32,33], several dietary compounds, such as anacardic acid [34], garcinol [35], curcumin [36], gallic acid [13], and EGCG [12], are reported to inhibit p300. Importantly, anacardic acid suppressed the expression of the NF-KB-regulated gene products by inhibiting p65 acetylating [37]. Similarly, silencing p300 using its siRNA plasmid transfection significantly enhanced RelA deacetylation and apoptosis induced by LA, implying a critical role of p300 in the apoptotic effect of LA.

Furthermore, LA suppressed NF-kB-regulated genes, including anti-apoptotic proteins (Bcl-2, Bcl-xL, XIAP, and Survivin), angiogenic and proliferative proteins (VEGF, Cox-2, and c-Myc), and inflammatory factors (IL-6 and TNF- $\alpha$ ), in MCF-7 cells.

MicroRNAs are well known to mediate cell differentiation, proliferation, and apoptosis [38]. Recent evidence revealed that miR134 induces apoptosis, and inhibits proliferation and migration by targeting the STAT3 in bladder cancer cells [39], and miR134 abrogates proliferation and EMT in renal cell carcinoma and colorectal cancer cells [17]. Here, LA upregulated the miRNA level of miRNA134 in MCF-7 cells, and also, the miRNA134-mimic abrogated the expression of p-STAT3, pro-PARP, and Ac-RelA, whereas the miRNA134-inhibitor reversed the ability of LA to inhibit the expression of pro-PARP and Ac-RelA in MCF-7 cells, indicating a critical role of miRNA134 in LA-induced apoptosis.

In summary, LA significantly increased the cytotoxicity, sub-G 1 population, and cleavage of PARP in MDA-MB-453, PC-3, MCF-7, and DU145 cells. Also, LA reduced the phosphorylation of STAT3 and NF- $\mathrm{kB}$, and disrupted the interaction between p-STAT3, p300, NF- $\mathrm{kB}$, and RelA/p65 acetylation in the MCF-7 and DU145 cells. Furthermore, LA reduced the nuclear translocation of STAT3 and $\mathrm{NF}-\mathrm{KB}$, and suppressed several survival genes, including Bcl-2, Bcl-XL, XIAP, survivin, VEGF, Cox-2, C-Myc, and IL-6, and TNF- $\alpha$ in MCF-7 cells. However, IL-6 blocked the apoptotic effect of LA, and the depletion of the STAT3- or p300-enhanced PARP cleavage of LA in MCF-7 cells. Notably, LA activated miRNA134, and so the miRNA134-mimic reduced the expression of p-STAT3, pro-PARP, and Ac-RelA, while the miRNA134 inhibitor reversed the apoptotic effect of LA in the MCF-7 cells. Taken together, these findings demonstrate that LA induces apoptosis via the miRNA-134 mediated inhibition of STAT3 and RelA/p65 acetylation (Figure 7). 


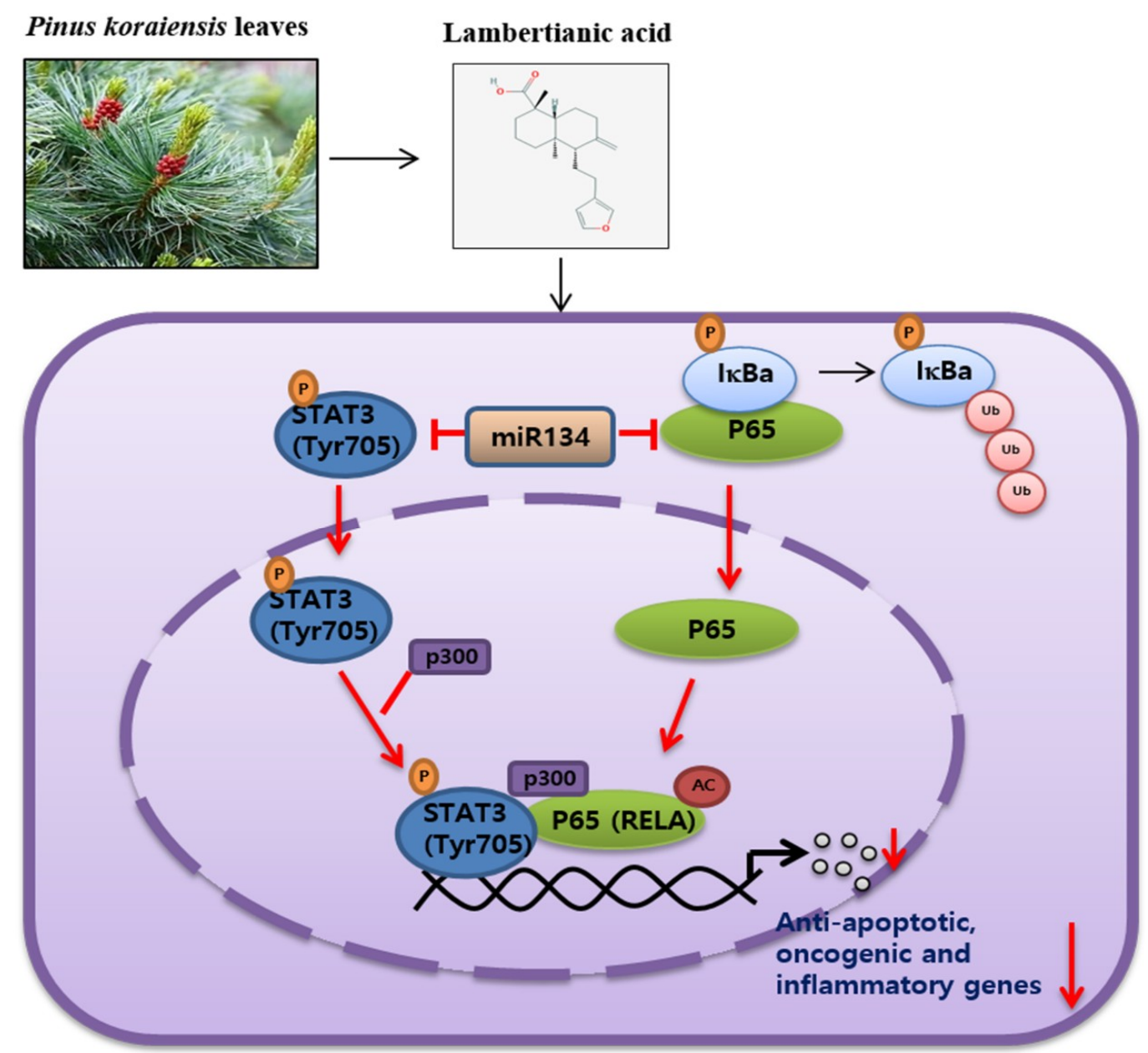

Figure 7. Schematic diagram on the apoptotic mechanism of LA in cancer cells via the miRNA-134-mediated inhibition of STAT3 and RelA/p65 acetylation.

\section{Materials and Methods}

\subsection{Isolation of Lambertianic Acid (LA)}

As shown in our papers [16,18], lambertianic acid (LA; molecular weight $=316.43)$ was isolated, purified, and identified as having over $98 \%$ purity, based on spectroscopic analyses such as nuclear magnetic resonance (NMR), mass spectrometry (MS), and infrared (IR) [40].

\subsection{Cell Culture}

Human breast cancers (MCF-7 (ATCC ${ }^{\circledR}$ HTB-22 ${ }^{\mathrm{TM}}$ ) and MDA-MB-453 (ATCC ${ }^{\circledR}$ HTB-131 ${ }^{\mathrm{TM}}$ )) and prostate cancer (DU145 (ATCC ${ }^{\circledR}$ HTB- $81^{\mathrm{TM}}$ ) and PC-3 (ATCC ${ }^{\circledR}$ CRL-1435 ${ }^{\mathrm{TM}}$ )) cells were obtained from the American Type Culture Collection (ATCC; Manassas, VA, USA). These cells were cultured in RPMI1640 supplemented with 10\% fetal bovine serum (FBS) and 1\% antibiotic (Welgene, Inc., Gyeongsan, South Korea) at $37^{\circ} \mathrm{C}$, under a humid environment with $5 \% \mathrm{CO}_{2}$.

\subsection{Cell Viability Assay}

The cytotoxicity of LA was evaluated by using a 3-(4,5-dimethylthiazol-2-yl)-2,5diphenyltetrazolium bromide (MTT) assay. Briefly, the MCF-7, MDA-MB-453, DU145, and PC-3 cells $\left(1 \times 10^{4}\right.$ cells/well) were exposed to indicated concentrations of LA for $24 \mathrm{~h}$, and were incubated with MTT $(1 \mathrm{mg} / \mathrm{mL})$; (Sigma Chemical, St. Louis, MO, USA) for $2 \mathrm{~h}$. Then, the cell viability was calculated as a percentage of 
the viable cells in the LA-treated group vs. the untreated control, with optical density (OD) values obtained using a microplate reader (Molecular Devices, LLC, Sunnyvale, CA, USA) at $570 \mathrm{~nm}$.

\subsection{Cell Cycle Analysis}

Based on Lee et al.'s paper [20], MCF-7 and MDA-MB-453 cells $\left(2 \times 10^{5}\right.$ cells $\left./ \mathrm{mL}\right)$ were exposed to LA $(0,15$, and $30 \mu \mathrm{M})$ for $24 \mathrm{~h}$, incubated with RNase A $(10 \mathrm{mg} / \mathrm{mL})$ for $1 \mathrm{~h}$ at $37^{\circ} \mathrm{C}$, and stained with propidium iodide $(50 \mu \mathrm{g} / \mathrm{mL})$. The stained cells were calculated for the DNA content by FACSCalibur (Becton Dickinson, Franklin Lakes, NJ, USA) using CellQuest Software.

\subsection{Western Blotting}

The cells were exposed to various concentrations of LA for $24 \mathrm{~h}$; lyzed in a lysis solution (50 mM Tris-HCl, pH 7.4, $150 \mathrm{mM} \mathrm{NaCl}, 1 \%$ Triton X-100, 0.1\% Sodium Dodecyl Sulfate (SDS), 1 mM EDTA, $1 \mathrm{mM} \mathrm{Na} \mathrm{VO}_{4}, 1 \mathrm{mM} \mathrm{NaF}$, and $1 \times$ protease inhibitor cocktail) on ice; and spun down at $14,000 \times g$ for $20 \mathrm{~min}$ at $4{ }^{\circ} \mathrm{C}$. The supernatants were collected and quantified for protein concentration using an reducing agent compatible (RC) detergent compatible (DC) protein assay kit (Bio-Rad, Hercules, CA, USA). The protein samples were separated on $4 \%-12 \%$ NuPAGE Bis-Tris gels (Novex, Carlsbad, CA, USA), and transferred to a Hybond ECL transfer membrane for detection with antibodies for cleaved-PARP, p-JAK2, p-STAT3, STAT3, p- p65/RelA, p65/RelA, p-IкB, p300, Ac-RelA, Bcl-2, Bcl-xL, XIAP, survivin, VEGF, COX-2, and c-Myc (Cell Signaling Technology, Beverly, MA, USA), as well as Bcl-2, XIAP, and COX-2 (Santa Cruz Biotechnology, Inc., Dallas, TX, USA), and $\beta$-actin (Sigma, St. Louis, MO, USA). The protein expression was measured using an enhanced chemiluminescence (ECL) system (Amersham Pharmacia, Piscataway, NJ).

\subsection{Immunofluorescence}

The cells fixed on a poly-L-lysine-coated slide in $4 \%$ paraformaldehyde were permeabilized in $0.1 \%$ Triton X-100, followed by immunostaining with goat polyclonal anti-phospho-STAT3 and rabbit polyclonal anti-p65 (Santa Cruz Biotechnology, Inc., Dallas, TX, USA) antibodies, using Goat and Rabbit IgG fluorescein isothiocyanate (FITC) antibody H\&L as a secondary antibody. The cells were mounted in a medium containing 4',6-diamidino-2-phenylindole (DAPI) and were photographed under an FLUOVIEW FV10i confocal microscopy (Olympus Corporation, Tokyo, Japan).

\subsection{Co-Immunoprecipitation}

The MCF-7 and DU145 cells were lyzed and immunoprecipitated with STAT3 and p300 antibodies. Thereafter, protein A/G sepharose beads (Santa Cruz Biotechnology, Santa Cruz, CA) were applied. The final precipitated proteins were subjected to immunoblotting with the indicated antibodies.

\subsection{RNA Interference}

The plasmids for p300-siRNA or control-siRNA ( $40 \mathrm{nM}$; Bioneer, Daejeon, Korea) were transiently transfected into MCF-7 cells for $24 \mathrm{~h}$, using an INTERFERinTM transfection reagent (Polyplustransfection Inc., New York, NY), according to manufacturer's protocols.

\subsection{RT-qPCR Analysis}

As shown in Matsuno et al.'s paper, the total RNA from the LA-treated MCF-7 cells was isolated by QIAzol (Invitrogen, Carlsbad, CA, USA) and subjected to regular processes of RT-qPCR using the following primers, IL-6-forward: 5'-CCACCGGGAACGAAAGAGAA-3'; reverse-5'-GAGAAGGCAACTGGACCGAA -3' (Bioneer, Daejeon, Korea), TNF- $\alpha$ - forward: $5^{\prime}$ GCCGCATCGCCGTCTCCTAC-3'; reverse- 5'-CCTCAGCCCCTCTGGGGTC -3' (Bioneer, Daejeon, Korea), hGAPDH-forward5'-CCA CTC CTC CAC CTT TGA CA-3'; ;reverse-5' -ACC CTG TTG CTG TAG CCA -3' (Bioneer, Daejeon, Korea). The mRNA level of glyceraldehyde-3-phosphate dehydrogenase 
(GAPDH) was used to normalize the expression of the genes of interest. Each sample was tested in triplicate, and the relative gene expression data were analyzed by means of the $2^{-\Delta \mathrm{CT}}$ method.

\subsection{MicroRNA Transfection Assay}

miR134-mimic, miR134-inhibitor, and miR-Con(200nM) plasmids (Bioneer, Daejeon, Korea) were transfected intoMCF-7 cells using an X-tremeGENE HP DNA Transfection Reagent (Roche, Basel, Switzerland), according to the manufacture's protocols.

\subsection{Statistical Analysis}

All of the values were expressed as means \pm standard deviation (SD). Sigmaplot version 12 software (Systat Software Inc., San jose, CA, USA) was used for the statistical analysis. Student $t$-test was used for comparison of two groups, and $p<0.05$ was considered as statistically significant.

\section{Conclusions}

Our findings suggest that LA significantly increased the cytotoxicity, sub G 1 population, and the cleavage of PARP in MDA-MB-453, PC-3, MCF-7, and DU145 cells. Also, LA reduced the phosphorylation of STAT3 and NF- $\mathrm{KB}$, and disrupted the interaction between p-STAT3, p300, NF-KB, and RelA/p65 acetylation in MCF-7 and DU145 cells. Furthermore, LA reduced the nuclear translocation of STAT3 and NF- $\mathrm{KB}$, and suppressed several survival genes, including Bcl-2, Bcl-XL, XIAP, survivin, VEGF, Cox-2, C-Myc, IL-6, and TNF- $\alpha$ in MCF-7 cells. However, IL-6 blocked the apoptotic effect of LA and the depletion of the STAT3- or p300-enhanced PARP cleavage of LA in MCF-7 cells. Notably, LA activated miRNA134, and so the miRNA134 mimic attenuated the expression of p-STAT3, pro-PARP, and Ac-RelA, while the miRNA134 inhibitor reversed the apoptotic effect LA in the MCF-7 cells. Taken together, these findings demonstrate that LA induces apoptosis via the miRNA-134 mediated inhibition of STAT3 and RelA/p65 acetylation

Author Contributions: D.Y.S. and H.-J.L. conceived and designed the experiments; J.H.J. and E.I. performed the experiments; J.H. and D.S.K. contributed to the data analysis; S.-H.K. wrote and edited the manuscript.

Funding: Foundation (KOSEF) grant funded by the Korea Government (no. 2017R1A2A1A17069297) and the grant of the "Cooperative Research Program for Agriculture Science and Technology Development" (project no. PJ01317002) was funded by the Rural Development Administration, Republic of Korea.

Acknowledgments: We thank members of the Kim laboratory for active discussion.

Conflicts of Interest: The authors declare no conflict of interest.

\section{Abbreviations}

STAT3 Signal transducers and activators of transcription 3

PARP Poly (ADP-ribose) polymerase

IL-6 Interleukin 6

PPI Protein-protein interaction

Ac-RelA RelA/p65 acetylation

HAT Histone acetyltransferase

\section{References}

1. Wang, Y.; van Boxel-Dezaire, A.H.; Cheon, H.; Yang, J.; Stark, G.R. STAT3 activation in response to IL-6 is prolonged by the binding of IL-6 receptor to EGF receptor. Proc. Natl. Acad. Sci. USA 2013, 110, 16975-16980. [CrossRef] [PubMed]

2. Matsuno, Y.; Kiwamoto, T.; Morishima, Y.; Ishii, Y.; Hizawa, N.; Hogaboam, C.M. Notch signaling regulates cell density-dependent apoptosis of NIH 3 T3 through an IL-6/STAT3 dependent mechanism. Eur. J. Cell Biol. 2018, 97, 512-522. [CrossRef] [PubMed] 
3. Garrido-Tapia, M.; Hernandez, C.J.; Ascui, G.; Kramm, K.; Morales, M.; Ga Rate, V.; Zuniga, R.; Bustamante, M.; Aguillon, J.C.; Catala, N.D.; et al. STAT3 inhibition by STA21 increases cell surface expression of MICB and the release of soluble MICB by gastric adenocarcinoma cells. Immunobiology 2017, 222, 1043-1051. [CrossRef] [PubMed]

4. Xu, G.; Zhu, L.; Wang, Y.; Shi, Y.; Gong, A.; Wu, C. Stattic enhances radiosensitivity and reduces radio-induced migration and invasion in HCC cell lines through an apoptosis pathway. BioMed Res. Int. 2017, 2017, 1832494. [CrossRef] [PubMed]

5. Affandi, I.S.M.; Lee, W.Q.; Feroz, S.R.; Mohamad, S.B.; Tayyab, S. Interaction of stattic, a STAT3 inhibitor with human serum albumin: Spectroscopic and computational study. J. Biomol. Struct. Dyn. 2017, 35, 3581-3590. [CrossRef] [PubMed]

6. Jahangiri, A.; Dadmanesh, M.; Ghorban, K. Suppression of STAT3 by S31-201 to reduce the production of immunoinhibitory cytokines in a HIF1-alpha-dependent manner: A study on the MCF-7 cell line. In Vitro Cell. Dev. Biol. Anim. 2018, 54, 743-748. [CrossRef] [PubMed]

7. Resetca, D.; Haftchenary, S.; Gunning, P.T.; Wilson, D.J. Changes in signal transducer and activator of transcription 3 (STAT3) dynamics induced by complexation with pharmacological inhibitors of Src homology 2 (SH2) domain dimerization. J. Biol. Chem. 2014, 289, 32538-32547. [CrossRef] [PubMed]

8. Johnston, P.A.; Grandis, J.R. STAT3 signaling: Anticancer strategies and challenges. Mol. Interv. 2011, 11, 18-26. [CrossRef]

9. Yu, H.; Pardoll, D.; Jove, R. STATs in cancer inflammation and immunity: A leading role for STAT3. Nat. Rev. Cancer 2009, 9, 798-809. [CrossRef]

10. Drazic, A.; Myklebust, L.M.; Ree, R.; Arnesen, T. The world of protein acetylation. Biochim. Biophys. Acta 2016, 1864, 1372-1401. [CrossRef]

11. Chen, L.F.; Greene, W.C. Shaping the nuclear action of NF-kappaB. Nat. Rev. Mol. Cell Biol. 2004, 5, $392-401$. [CrossRef] [PubMed]

12. Choi, K.C.; Jung, M.G.; Lee, Y.H.; Yoon, J.C.; Kwon, S.H.; Kang, H.B.; Kim, M.J.; Cha, J.H.; Kim, Y.J.; Jun, W.J.; et al. Epigallocatechin-3-gallate, a histone acetyltransferase inhibitor, inhibits EBV-induced B lymphocyte transformation via suppression of RelA acetylation. Cancer Res. 2009, 69, 583-592. [CrossRef] [PubMed]

13. Choi, K.C.; Lee, Y.H.; Jung, M.G.; Kwon, S.H.; Kim, M.J.; Jun, W.J.; Lee, J.; Lee, J.M.; Yoon, H.G. Gallic acid suppresses lipopolysaccharide-induced nuclear factor-kappaB signaling by preventing RelA acetylation in A549 lung cancer cells. Mol. Cancer Res. 2009, 7, 2011-2021. [CrossRef] [PubMed]

14. Tsai, Y.J.; Tsai, T.; Peng, P.C.; Li, P.T.; Chen, C.T. Histone acetyltransferase p300 is induced by p38MAPK after photodynamic therapy: The therapeutic response is increased by the p300HAT inhibitor anacardic acid. Free Radic. Biol. Med. 2015, 86, 118-132. [CrossRef] [PubMed]

15. Ryan, B.C.; Werner, T.S.; Howard, P.L.; Chow, R.L. ImiRP: A computational approach to microRNA target site mutation. BMC Bioinform. 2016, 17, 190. [CrossRef]

16. Ye, Q.; Su, L.; Chen, D.; Zheng, W.; Liu, Y. Astragaloside IV induced miR-134 expression reduces EMT and increases chemotherapeutic sensitivity by suppressing CREB1 signaling in colorectal cancer cell line SW-480. Cell. Physiol. Biochem. Int. J. Exp. Cell. Physiol. Biochem. Pharmacol. 2017, 43, 1617-1626. [CrossRef]

17. Liu, Y.; Zhang, M.; Qian, J.; Bao, M.; Meng, X.; Zhang, S.; Zhang, L.; Zhao, R.; Li, S.; Cao, Q.; et al. miR-134 functions as a tumor suppressor in cell proliferation and epithelial-to-mesenchymal Transition by targeting KRAS in renal cell carcinoma cells. DNA Cell Biol. 2015, 34, 429-436. [CrossRef]

18. Lee, M.S.; Cho, S.M.; Lee, M.H.; Lee, E.O.; Kim, S.H.; Lee, H.J. Ethanol extract of Pinus koraiensis leaves containing lambertianic acid exerts anti-obesity and hypolipidemic effects by activating adenosine monophosphate-activated protein kinase (AMPK). BMC Complement. Altern. Med. 2016, 16, 51. [CrossRef]

19. Chae, H.S.; Chin, Y.W. Anti-allergic effect of lambertianic acid from Thuja orientalis in mouse bone marrow-derived mast cells. Immunopharmacol. Immunotoxicol. 2012, 34, 250-255. [CrossRef]

20. Lee, J.H.; Lee, H.J.; Sim, D.Y.; Jung, J.H.; Kim, K.R.; Kim, S.H. Apoptotic effect of lambertianic acid through AMPK/FOXM1 signaling in MDA-MB231 breast cancer cells. Phytother. Res. 2018, 32, 1755-1763. [CrossRef]

21. Jeong, A.; Kim, J.H.; Lee, H.J.; Kim, S.H. Reactive oxygen species dependent phosphorylation of the liver kinase B1/AMP activated protein kinase/acetyl-CoA carboxylase signaling is critically involved in apoptotic effect of lambertianic acid in hepatocellular carcinoma cells. Oncotarget 2017, 8, 70116-70129. [CrossRef] [PubMed] 
22. Lee, M.S.; Lee, S.O.; Kim, S.H.; Lee, E.O.; Lee, H.J. Anti-cancer effect of lambertianic acid by inhibiting the AR in LNCaP cells. Int. J. Mol. Sci. 2016, 17, 1066. [CrossRef] [PubMed]

23. Lieblein, J.C.; Ball, S.; Hutzen, B.; Sasser, A.K.; Lin, H.J.; Huang, T.H.; Hall, B.M.; Lin, J. STAT3 can be activated through paracrine signaling in breast epithelial cells. BMC Cancer 2008, 8, 302. [CrossRef] [PubMed]

24. He, G.; Karin, M. NF-kappaB and STAT3-key players in liver inflammation and cancer. Cell Res. 2011, 21, 159-168. [CrossRef] [PubMed]

25. Grivennikov, S.I.; Karin, M. Dangerous liaisons: STAT3 and NF-kappaB collaboration and crosstalk in cancer. Cytokine Growth Factor Rev. 2010, 21, 11-19. [CrossRef]

26. Kaliyaperumal, K.; Sharma, A.K.; McDonald, D.G.; Dhindsa, J.S.; Yount, C.; Singh, A.K.; Won, J.S.; Singh, I. S-Nitrosoglutathione-mediated STAT3 regulation in efficacy of radiotherapy and cisplatin therapy in head and neck squamous cell carcinoma. Redox Biol. 2015, 6, 41-50. [CrossRef]

27. Gong, J.; Xie, J.; Bedolla, R.; Rivas, P.; Chakravarthy, D.; Freeman, J.W.; Reddick, R.; Kopetz, S.; Peterson, A.; Wang, H.; et al. Combined targeting of STAT3/NF-kappaB/COX-2/EP4 for effective management of pancreatic cancer. Clin. Cancer Res. 2014, 20, 1259-1273. [CrossRef]

28. Kim, J.W.; Jang, S.M.; Kim, C.H.; An, J.H.; Kang, E.J.; Choi, K.H. New molecular bridge between RelA/p65 and NF-kappaB target genes via histone acetyltransferase TIP60 cofactor. J. Biol. Chem. 2012, 287, 7780-7791. [CrossRef]

29. Lee, H.; Herrmann, A.; Deng, J.H.; Kujawski, M.; Niu, G.; Li, Z.; Forman, S.; Jove, R.; Pardoll, D.M.; Yu, H. Persistently activated Stat3 maintains constitutive NF-kappaB activity in tumors. Cancer Cell 2009, 15, 283-293. [CrossRef]

30. Hoesel, B.; Schmid, J.A. The complexity of NF-kappaB signaling in inflammation and cancer. Mol. Cancer 2013, 12, 86. [CrossRef]

31. Oh, J.H.; Cho, M.C.; Kim, J.H.; Lee, S.Y.; Kim, H.J.; Park, E.S.; Ban, J.O.; Kang, J.W.; Lee, D.H.; Shim, J.H.; et al. IL-32gamma inhibits cancer cell growth through inactivation of NF-kappaB and STAT3 signals. Oncogene 2011, 30, 3345-3359. [CrossRef] [PubMed]

32. Singh, B.N.; Zhang, G.; Hwa, Y.L.; Li, J.; Dowdy, S.C.; Jiang, S.W. Nonhistone protein acetylation as cancer therapy targets. Expert Rev. Anticancer Ther. 2010, 10, 935-954. [CrossRef] [PubMed]

33. Di Martile, M.; Del Bufalo, D.; Trisciuoglio, D. The multifaceted role of lysine acetylation in cancer: Prognostic biomarker and therapeutic target. Oncotarget 2016, 7, 55789-55810. [CrossRef] [PubMed]

34. Sun, Y.; Jiang, X.; Chen, S.; Price, B.D. Inhibition of histone acetyltransferase activity by anacardic acid sensitizes tumor cells to ionizing radiation. FEBS Lett. 2006, 580, 4353-4356. [CrossRef] [PubMed]

35. Arif, M.; Pradhan, S.K.; Thanuja, G.R.; Vedamurthy, B.M.; Agrawal, S.; Dasgupta, D.; Kundu, T.K. Mechanism of p300 specific histone acetyltransferase inhibition by small molecules. J. Med. Chem. 2009, 52, 267-277. [CrossRef] [PubMed]

36. Marcu, M.G.; Jung, Y.J.; Lee, S.; Chung, E.J.; Lee, M.J.; Trepel, J.; Neckers, L. Curcumin is an inhibitor of p300 histone acetylatransferase. Med. Chem. 2006, 2, 169-174.

37. Sung, B.; Pandey, M.K.; Ahn, K.S.; Yi, T.; Chaturvedi, M.M.; Liu, M.; Aggarwal, B.B. Anacardic acid (6-nonadecyl salicylic acid), an inhibitor of histone acetyltransferase, suppresses expression of nuclear factor-kappaB-regulated gene products involved in cell survival, proliferation, invasion, and inflammation through inhibition of the inhibitory subunit of nuclear factor-kappaBalpha kinase, leading to potentiation of apoptosis. Blood 2008, 111, 4880-4891.

38. Sassen, S.; Miska, E.A.; Caldas, C. MicroRNA: Implications for cancer. Virchows Arch. Int. J. Pathol. 2008, 452, 1-10. [CrossRef]

39. Wang, S.; Wu, G.; Han, Y.; Song, P.; Chen, J.; Wu, Y.; Yang, J.; Liang, P. miR-124 regulates STAT3-mediated cell proliferation, migration and apoptosis in bladder cancer. Oncol. Lett. 2018, 16, 5875-5881. [CrossRef]

40. Yang, X.; Ding, Y.; Sun, Z.H.; Zhang, D.M. [Studies on chemical constituents of Pinus armandii]. Acta Pharm. Sin. 2005, 40, 435-437.

(C) 2019 by the authors. Licensee MDPI, Basel, Switzerland. This article is an open access article distributed under the terms and conditions of the Creative Commons Attribution (CC BY) license (http://creativecommons.org/licenses/by/4.0/). 